Abstracta Iranica Abstracta Iranica

Revue bibliographique pour le domaine irano-aryen

Volume 26 | 2005

Comptes rendus des publications de 2003

Qajar Studies. Journal of the International Qajar Studies Association. Vol. III, Rotterdam, IQSA Publications, 2003.

Monik Kervran

(2) OpenEdition

Journals

Édition électronique

URL : http://journals.openedition.org/abstractairanica/2520

ISSN : 1961-960X

Éditeur :

CNRS (UMR 7528 Mondes iraniens et indiens), Éditions de I'IFRI

Édition imprimée

Date de publication : 15 mai 2005

ISSN : 0240-8910

Référence électronique

Monik Kervran, "Qajar Studies. Journal of the International Qajar Studies Association. Vol. III, Rotterdam IQSA Publications, 2003. ", Abstracta Iranica [En ligne], Volume 26 | 2005, document 286, mis en ligne le 07 décembre 2005, consulté le 25 septembre 2020. URL : http://journals.openedition.org/ abstractairanica/2520

Ce document a été généré automatiquement le 25 septembre 2020.

Tous droits réservés 


\title{
Qajar Studies. Journal of the International Qajar Studies Association. Vol. III, Rotterdam, IQSA Publications, 2003.
}

\author{
Monik Kervran
}

1 «Iranian Heraldry: The History of the Qajar Coat of Arms and a Forgotten Tradition of Heraldic Art in Persia »(pp.9-29), par A. K.Zarrinkafsh, est une pérégrination sur l'origine du motif lion / soleil, adopté au $19^{\mathrm{e}} \mathrm{s}$. par le chef de la dynastie Qajar, d'autres branches de la famille et quelques villes d'Iran. Il symbolise, dès l'époque pré-slamique, la monarchie de droit divin à laquelle s'est ajouté le glaive de la foi islamique, devenu celui du shiisme.

2 «Prince Abbas Mirza (Salar Lashgar, Farman Farmaian), young man with a camera " (pp.31-61), par B.F. Farmaian. Interessant parcours photographique de la vie de ce prince, né en 1890 d'une fille de Mozaffar ed-Dīn Šāh. Grand amateur de photographies il en laissa beaucoup. L'A. a sélectionné celles qui le montrent à Harrow, à Sandhurst, parmi les Chasseurs Alpins en 1908-1909, dans la Commission Militaire anglo-persane de 1919, mais aussi en villégiature en Suisse, à Istanbul ou à Berlin.

3 « Forgotten Artists from the Golestan Palace: drawings and calligraphie by Nasser edDin Shah and Malikak in the Bayani Collection» (pp.63-69), par B. Bayani : quatre dessins et quelques calligraphies du premier et trois caricatures du second.

4 «Qajar Imperial attire: The making of Persia's Lion and Sun King, Fath Ali Shah Qajar » (pp. 70-93), par M.M. Eskandari-Qajar. Comment l'image parfaite du souverain en majesté, coiffé de la couronne-tiare, correspondait à la consolidation du pouvoir de la dynastie et à une étiquette très élaborée qui empruntait à celle des Zand et des Sefevides.

5 "Cloth for spécial occasions: the Arts of Qajar Court dress» (pp.95-110), par J. M. Scarce. Un peu sur le même thème, l'A. évoque l'importance du costume d'apparat pour les souverains qajars dans l'expression du pouvoir, mais aussi l'offre et le port de 
textiles précieux en des occasions bien déterminées comme Nowrūz ou le ta'ziye, dont les représentations étaient très populaires sous les Qajars, en ville comme à la campagne.

INDEX

Thèmes : 5.1. Monde iranophone

\section{AUTEURS}

MONIK KERVRAN

CNRS - Paris 